\title{
Muestra Estatal de TEATRO: 28 AÑOS DE ACTIVIDAD ESCÉNICA
}

CARLOS URANI MONTIEL CONTRERAS ${ }^{1}$

AMALIA RODRÍGUEZ ISAIS ${ }^{2}$

\section{RESUMEN}

on casi tres décadas de realización consecutiva, la Muestra Estatal de Teatro (MET) en Chihuahua es fundamental para comprender el quehacer escénico regional en su articulación con el teatro nacional. Nuestro objetivo principal consiste en una valoración crítica de su última edición, la número 28, a partir de un análisis sincrónico y diacrónico que se ocupe del origen y trayectoria tanto de la MET como de las compañías que se dieron cita en la región de Delicias del 17 al 22 de agosto del año pasado. La crítica teatral de los montajes programados será el punto de inflexión para apreciar el estado del arte del teatro chihuahuense contemporáneo.

Palabras clave: crítica teatral, puesta en escena, festival, dramaturgia, compañías.

1 Docente investigador en la Universidad Autónoma de Ciudad Juárez.

2 Maestra en Estudios Literarios por la Universidad Autónoma de Ciudad Juárez. 


\begin{abstract}
With almost three decades of consecutive performance, the MET in Chihuahua is essential to understand the regional stage work in context with the national scene. Our main objective consists of a critical evaluation of its latest edition, the 28th, based on a synchronous and diachronic analysis that deals with the origin and trajectory of both MET and the companies that participated in the Delicias Region from August the 17th to the 22nd of last year. Theatre criticism of the programmed productions will be the turning point to appreciate the state of the art that contemporary Chihuahua theatre is in right now.
\end{abstract}

Keywords: theatre criticism, performance, festival, dramaturgy, troupes.

Muestra Estatal de Teatro: 28 años de actividad escénica Que el teatro es el quetzal, no cualquiera puede alcanzarlo; grandes genios lo intentaron sin lograrlo. Es el Ave Fénix. Carlos Montemayor agregó después que a los teatreros nomás les faltó decir que el teatro era el águila devorando a la serpiente.

Jesús Chávez Marín, "Voces en tierra blanca”, 1984.

\title{
INTRODUCCIÓN
}

La crónica de Jesús Chávez Marín, compuesta seis años antes de la primera Muestra Estatal de Teatro (MET), revela una instantánea sobre el estatus de los teatristas con relación a la comunidad de intelectuales que se dieron cita en la Segunda Asamblea de Escritores Chihuahuenses. La imagen coincide con el antiguo debate sobre la adscripción del género dramático, "que solo cobra vida dentro del escenario", a la literatura. La "oreja gráfica" del cronista registra pormenores y ecos de pasillos. "Uno de los asuntos que mejor se trataron fue el teatro”. ¿Qué temas? Los de siempre: 
el traslado de la autoría del texto escrito al ego del director, la programación en los complejos culturales y el equipamiento de los inmuebles. Para completar el panorama, un conferencista concluyó:

Ensayamos seis meses para subir a escena dos días; temporadas brevísimas y frustradas. Se hace uso ineficiente de la publicidad y a manera de crítica publicamos gacetillas que nomás nosotros leemos. No se consolida una acción permanente y armónica del teatro regional (Chávez Marín, 2014: 30-31).

Subrayamos, en este visionario diagnóstico, la constancia y el concierto como elementos sustantivos para accionar la práctica de un gremio que cierra filas, pero que - con frecuencia, antes de buscar aliados fuera de las tablas - suele distanciarse de otras comunidades creativas. De ahí que el poeta y novelista parralense, Carlos Montemayor, pilar de las letras del norte de México, haya expuesto con humor la sobrevaloración de la disciplina.

Veintiocho años representan apenas un fragmento del teatro que se ha producido en "el estado grande"; no obstante, el establecimiento de las MET a nivel federal, así como su doble articulación, primero, con las muestras regionales (a las que acceden las obras ganadoras de cada entidad) y, después, con la Muestra Nacional de Teatro (MNT), la cual celebró el pasado noviembre su emisión número 40, nos habla de una práctica paralela en la que las diferentes teatralidades mexicanas se han venido desarrollando. Por tanto, para cualquier estado, la MET resulta fundamental para comprender el quehacer escénico regional en diálogo permanente con el nacional. La coyuntura anual entre estos niveles -estado, región, nación - perfila a las muestras como una plataforma de exhibición para un público determinado (los propios teatristas y programadores), pero, sobre todo, como un espacio de reconocimiento al empeño de las compañías y de encuentro entre pares, incluidos aquí estudiosos y críticos. ${ }^{3}$

3 Nuestro colectivo, Norteatro, se dedica a la crítica teatral (a través de nuestra plataforma www.norteatro.com), así como a la consolidación y formación de públicos, gracias a la intervención que realizamos en los eventos más relevantes en Ciudad Juárez: Festival Internacional del Drama Español Siglo de Oro, Festival de Teatro 
Para 2021, la MET Chihuahua habrá cumplido tres décadas. A pesar de su longevidad, no existen registros bibliográficos que comenten o estudien alguna de sus 28 emisiones, por lo que consideramos urgente, de ahora en adelante, guardar memoria de cada una desde más allá de la nota periodística, la anécdota (como en el caso de la biografía del actor Óscar Erives: El otro Oscar. Peripecias de un teatrista chihuahuense) o los programas de mano. ${ }^{4}$ De gran utilidad ha sido el documental $A$ telón abierto: 25 años de la MET (Sierra, 2016) para escuchar a los protagonistas, sin intermediario visible, expresarse de una tradición sustentada en su arte.

El objetivo primario del presente ensayo consiste, entonces, en una valoración crítica de la última MET, la 28, celebrada en la región de Delicias del 17 al 22 de agosto de 2019, en "Homenaje a Emesto Ochoa Guillemard", formador de actores y directores en Ciudad Juárez. ${ }^{5}$ En un primer apartado, repasamos de manera sucinta los antecedentes y detallamos los cometidos -en materia de políticas públicas en el ramo de cultura- de la MET. Este proceder sincrónico nos servirá de preámbulo para trazar el origen y trayectoria de las compañías que, tras responder a la convocatoria emitida por la Secretaría de Cultura, acudieron al evento para

de la Ciudad (ambos organizados por el Municipio) y Festival Internacional Teatro sin Fronteras (gestionado por la compañía Telón de Arena). Gracias al vínculo con la Secretaría de Cultura de Chihuahua, hemos participado como críticos en la MET durante tres años consecutivos. Además de los que aquí suscriben, Grecia Márquez, becaria de la Maestría en Estudios Literarios en la UACJ y coordinadora de la Escuela de Espectadores en la localidad, también forma parte de Norteatro.

4 Aunque hemos acompañado la programación de la MET desde 2017 a través de desmontajes (entrevista con las compañías inmediatamente después de la función) y críticas teatrales de cada puesta, fue hasta el año pasado que realizamos un balance general de la MET 27. Véase C. U. Montiel Contreras, "La Muestra Estatal de Teatro de Chihuahua 2018: desmontajes y reseñas”, Investigación Teatral 15.10 (2019): 178193.

5 Muerto de manera trágica a sus 79 años en el corredor Gómez Morín de Ciudad Juárez. Nos importa asentar las condiciones del sentido fallecimiento, ocurrido el 8 de septiembre de 2018, ya que en las distintas exequias (incluida la develación de una placa con la que se le agregó el nombre del maestro al Centro Cultural de la Ciudad, por todos conocido como el Teatro del INBA) se eximió cuidadosamente la responsabilidad del Municipio de atender la seguridad de los peatones -más aún la de los de la tercera edad- El tránsito en esa vía favorece a los automovilistas para que se desplacen aprisa entre bares y restaurantes. Más adelante, hacia el final del ensayo, añadiremos una nota final sobre la calidez de Ochoa Guillemard. 
montar sus obras. La crítica teatral de las puestas en escena de Los habitantes inútiles, La Bodega, 1939 Teatro Norte, Telón de Arena y Teatro Bárbaro es el punto de inflexión (diacrónico) para apreciar el estado del arte del teatro chihuahuense actual.

\section{LAS MET EN EL ESTADO GRANDE}

Rastrear la historia de la MET en Chihuahua implica un trabajo documental y hemerográfico que sobrepasa las intenciones, condiciones de escritura (debido a la contingencia sanitaria) y extensión del presente artículo. La alternancia en el gobierno estatal, con las subsecuentes remociones, y hasta cambio de nombre, en la dependencia encargada de la administración y promoción de la cultura, ha impedido que exista una carpeta única sobre la muestra o un registro cronológico con convocatorias, participantes, jurados y distinciones.

La primera MET oficial reconocida por el INBA fue organizada por la Asociación de Teatristas Unidos de Chihuahua en 1991 en el Teatro de Cámara de la capital. Antes de esta fecha, ya se habían celebrado festivales con representantes de distintos municipios; incluso Chihuahua ya había figurado en el certamen nacional, en la VII MNT de 1984, para ser exactos. ${ }^{6}$ De esta manera, 1991 resulta señero por la iniciativa de incluirse como entidad a los circuitos de exhibición oficiales, así como a los procesos y vías de selección, lo que supuso un repunte estético en materia escénica. Al año siguiente, el recién fundado Instituto Chihuahuense de la Cultura (ICHICULT) participó en la coorganización; a mediados de la década, el Instituto empezó a gestionar el evento de manera independiente. Con la administración panista en curso, el ICHICULT, tras 24 años en funciones, fue renombrado en 2016 como Secretaría de Cultura del Gobierno del Estado de Chihuahua (encabezada por María Concepción Landa), organismo encargado de la MET 28, que aquí nos ocupa.

6 Se trató de La casa de Bernarda Alba, de Federico García Lorca, montada por el Instituto Tecnológico de Ciudad Juárez (Partida Tayzan, 2008: 41) y dirigida por —ni más ni menos que - Ernesto Ochoa Guillemard, fundador en 1980 del grupo Aleph del ITCJ. 
Ante este vaivén político, el propio archivo de cada compañía luce como otra fuente privilegiada de información, así como la memoria oral de aquellos que cimentaron la tradición anual del reencuentro e intercambio. Ese fue el proceder tanto de Héctor Padilla, investigador en Ciencias Sociales adscrito a la UACJ, para articular una colección de once entrevistas publicadas en Telón de Voces: el teatro en Ciudad Juárez 1980-2002 (2005), como de Cynthia Angélica Rodríguez, última coordinadora de Artes Escénicas del Ichicult, junto con el director Luis Sierra, para celebrar el cuarto de siglo de la MET con el documental ya antes mencionado, producido con fondos estatales. A telón abierto recoge los testimonios grabados en entrevistas con Ernesto Medina (actor y director), Jesús Chávez Marín (escritor), Manuel Talavera Trejo (director, dramaturgo y catedrático de la $\mathrm{UACH}$, fallecido en mayo de 2017), Elsa Sáenz (actriz y docente), Jesús Ramírez (actor y director), Perla de la Rosa (actriz, dramaturga, directora y catedrática de la UACJ), Edeberto "Pilo" Galindo (dramaturgo y director), José Luis Acosta (actor y director), Sergio Juárez (actor y director) e Iván Carlos Hernández (promotor cultural y funcionario público aún activo). El video (disponible en el canal de YouTube de Sierra Media Labs) muestra fotografías de montajes, notas de periódico y material publicitario proporcionado por Oscar Erives, Antonio Zúñiga, Guadalupe de la Mora, entre otros, así como descargado de blogs que resguardan y promocionan la cultura regional: Tramoyam y Juaritos Literario.?

Nos parece ineludible, por otra parte, cotejar este repertorio de fuentes con el discurso institucional y de carácter jurídico que, siendo ajeno a la producción dramática, dicta normas de operación previas a la inauguración; dispone y distribuye fondos tanto para las agrupaciones como para las actividades complementarias que nutren a la MET; asigna los espacios de montaje y traza las líneas curatoriales, ya que selecciona y paga honorarios de la ter-

7 Tramoyam (https://tramoyam.blogspot.com/) a cargo del director y profesor Martín Hernández Molina, lleva funcionando en línea más de 15 años como hemeroteca del Estado, sobre todo de la capital. Por nuestra parte, el proyecto de investigación Cartografía literaria de Ciudad Juárez (www.juaritosliterario.com) difunde y reseña, desde marzo de 2016, las obras de ficción que recrean en sus páginas la región fronteriza. 
na de jueces. Es un hecho que, en materia de política pública, la gestión en torno al diseño de la convocatoria y de la programación condiciona el éxito de la MET. La experiencia inmediata, obtenida en Ciudad Juárez en la edición 27, había sido lo suficientemente amarga como para desatender los fallos que llevaron al jurado, en aprecio a su tiempo y trayectoria, a desentenderse de la propia planeación de la justa en la que participaban. ${ }^{8}$

La Secretaría de Cultura emitió la Convocatoria en junio, en cumplimiento del Plan estatal de desarrollo 2017-2021 y el Programa sectorial de cultura como derecho humano. Los lineamientos del primer documento establecen prioridades para procurar el bienestar general; de esta guía, importa aquí el primero de los cinco ejes rectores; es decir, el área de Desarrollo humano y social, que incluye uno de los principales desafíos de la administración: impulsar el progreso social, económico, político y, por supuesto, cultural. Aunque la mayoría de las metas se concentran en cuestiones de salud y educación, la cultura también figura como un derecho. El objetivo 18, por ejemplo, consiste en "Promover y difundir las expresiones artísticas y culturales de la entidad en el ámbito regional, nacional e internacional" (Gobierno del Estado, 2017a: 90), lo cual implica ampliar tanto el acceso de la población como la oferta de las manifestaciones. En este contexto, la MET funge como una actividad encaminada a solventar este propósito, sobre todo cuando la sede abandona los centros urbanos.

El Programa Sectorial de la Secretaría de Cultura es un instrumento de planeación estratégica en el que se plasman los objetivos y las líneas de acción a implementar de la dependencia que lo titula. La convocatoria de la MET se apega concretamente al primero de sus cuatro propósitos, lo cual no significa que se deslinde del resto: "Desarrollar el arte y la cultura en todas sus manifestaciones". Para lograrlo, se estableció una decena de estrategias; sin embargo, la Muestra abarca, sobre todo, las tres iniciales:

8 Maribel Carrasco, Aristeo Mora y Alberto Villarreal solo postularon a la obra representante para la Regional: El caimán y los sapos de 1939 Teatro Norte, escrita por "Pilo" Galindo. En cuanto a mejor director, escenografía, actores y dramaturgia, sentenciaron "que no hubo condiciones suficientes para deliberar sobre quiénes merecían reconocimiento individual. El escrutinio se hizo polvo y desierto" (Montiel, 2019: 181). 
1) Atender de manera directa a las y los artistas y creadores del Estado apoyando proyectos de producción, desarrollo y difusión artística; 2) Atender las necesidades culturales de la sociedad chihuahuense ofreciendo actividades de calidad y propuestas artísticas innovadoras; y 3) Capacitar y profesionalizar a promotores y gestores culturales en su práctica laboral y en el desarrollo de proyectos culturales y artísticos. (Gobierno del Estado, 2017b: 29)

La crítica teatral Grecia Márquez, quien asistió junto con nosotros a Delicias, publicó un balance general, "A ocho meses de la MET 28 en Chihuahua”, sobre la gestión y curaduría. De esas líneas, sintetizamos cuatro aspectos acerca de la proveniencia de los fondos, las sedes, los invitados (talleristas y jurados) y, por último, la programación.

La actual política de austeridad ha golpeado a las artes. A cualquier práctica cultural que se aleje (o cuestione) los programas asistencialistas se le tilda de privilegio, mermando sus arcas; más aún si la entidad no coincide con el partido en el poder. Varias muestras estatales en la república se cancelaron; en Chihuahua se respiraba incertidumbre. De forma inédita, la Secretaría de Cultura unió presupuestos y espacios con el Festival Internacional Chihuahua, que se alimenta de fondos mixtos de empresas privadas. Para cuando la MET se inauguró el 17 de agosto en el Teatro de la Ciudad Manuel Talavera con la función de Nacahue: Ramón y Hortensia, el FICH, en la misma región de Delicias, llevaba ya unos días, y se prolongó unos más, del 14 al 19. ${ }^{9}$ Esta medida, sin la cual no hubiera habido muestra, devino en dos situaciones. Por un lado, Andrea Montes Olivas, coordinadora del FICH, generó las condiciones para que la comunidad teatral reflexionara sobre su propio quehacer. Ella y su equipo, a sabiendas del rescate, mostraron un interés genuino por un gremio y un evento con el que no habían trabajado de forma exclusiva. Por otro, la imagen tanto del

9 Debido a su cualidad de foránea, no incluimos en nuestro estudio la función inaugural de Colochos Teatro, de la Ciudad de México, dirigida por Juan Carrillo, que meses después se presentó en la Nacional. 
FICH como la MET era idénticas, al grado de confundirse. Sin una campaña publicitaria independiente, la asistencia a las puestas en escena se limitó a las demás compañías. Teatro para teatreros.

El centralismo del estado, contra toda lógica matemática, lo ocupan dos núcleos urbanos. Por años, la capital y Ciudad Juárez habían recibido a los artistas con largas filas y teatros llenos. La MET 28, en concordancia con las directrices del FICH y sus caravanas, se trasladó a la región sureste, involucrando a varios municipios, además de la sede principal, como Camargo, Saucillo y Meoqui, donde el aforo mejoró respecto a Delicias; no obstante, los inmuebles carecían de las condiciones adecuadas - tramoya, cabina de control, iluminación, climatización- para espectáculos profesionales en competencia. Esto ocurrió, sobre todo, en Saucillo y Meoqui donde platicamos con algunos espectadores (en su mayoría jóvenes) que asistieron sin saber que iban a ver una puesta en escena ni que, mucho menos, era parte de la Muestra Estatal. La creación de públicos requiere de ciertas estrategias bien meditadas; presenciar teatro a $40^{\circ}$ centígrados no se cuenta entre ellas.

El jurado se compuso por una terna masculina: Sergio Galindo, director y dramaturgo de reconocido prestigio nacional; Juan Francisco Carrillo Esparza, actor y director de la pieza inaugural y Ricardo Salgado López, escenógrafo. La Convocatoria garantizaba la contratación de "profesionales del medio teatral para seleccionar los montajes [...] programados en la Muestra, así como para dictaminar a las y los ganadores de las categorías especiales" (Gobierno del Estado, 2019: 1). A excepción del miembro de Colochos, los otros dos jurados ofrecieron talleres en sus áreas de especialización. De manera complementaria, Sara Pinedo, directora del Colectivo de Teatro Comunitario Los de Abajo, de Guanajuato, impartió otro taller sobre teatro de invasión. La programación se completó con una serie de encuentros y conferencias.

Dentro de estas últimas actividades, el colectivo Norteatro, al que pertenezco, se encargó de dar una plática sobre la migración en el teatro regional y coordinar, cada noche, los Encuentros de reflexión e intercambio (ERI). En un afán documental y analítico, reseñamos todas las escenificaciones -incluidas las dos no con- 
cursantes-, con lo que, además de la crítica sobre lo acontecido en las tablas, promovemos la preservación de la memoria (Márquez, 2020).

En cuanto a las puestas en escena, presenciamos un total de once a cargo de ocho compañías. De Ciudad Juárez asistieron Telón de Arena (con dos), 1939 Teatro Norte (con otro par) y Taller de Teatro; mientras que de la capital, Strongylus, Los Habitantes Inútiles, La Bodega y Teatro Bárbaro (también con dos producciones). Pese al traslado del evento, las dos ciudades de siempre acapararon los escenarios; a excepción de un grupo amateur invitado, Tras-Luz, que representó de manera destacable a Meoqui con un drama histórico, Juicio a Malinche, escrito y dirigido por Adalberto G. Vela Vázquez. A continuación, nos centramos en la crítica teatral de las obras que se llevaron los reconocimientos: Auroras boreales de Los Habitantes Inútiles, Soy Bernarda Alba de La Bodega, Filos y Millenials de 1939 Teatro Norte, King Tiger y A la orilla del río de Telón de Arena, Derivas y Arrullos para Benjamín de Teatro Bárbaro. Dejamos fuera del estudio, pero no de nuestro interés, otros dos montajes por no ser profesionales: Hablemos de panzas de Taller de Teatro, escrito y dirigido por Rubén Torres; y Ni con palabras, de Strongylus, escrito y dirigido por Javier López Ríos. ${ }^{10}$

Año con año, la MET se dispone a solventar las metas que dicta su propia normativa; en esta ocasión, nos parece que hubo un avance significativo en las reglas de operación. Si la convocatoria de 2018 parecía sancionar la producción excesiva al admitir solo una obra por compañía, este error se corrigió, ya que ahora se permitía que un mismo director de escena fungiera "como tal en un máximo de dos montajes (sin excluirse con esto su participación creativa en estos u otros montajes), a fin de privilegiar la rotación de creadores y la participación de artistas" (Gobierno del Estado, 2019: 1). Otro acierto fue que se levantó, por fin, la restricción a la actuación de menores de edad que, a la postre, permitió

10 De las tres puestas en escena no contempladas, escribimos sendas críticas disponibles en nuestro blog: www.norteatro.com. De cierta forma, el dictamen del jurado concuerda con nuestra selección. 
que Arrullos para Benjamín fuera seleccionada para representar a Chihuahua en la Muestra Regional, aunque esta se canceló por falta de fondos, ya que iba a celebrarse en nuestro Estado. De no blindarse los recursos anuales para la MET, de poco sirven los avances en materia normativa; si no se legisla a favor del teatro como herramienta de transformación social, cada nueva administración comenzará a trabajar de cero con artistas que llevan décadas dejándolo todo en las tablas.

\section{LOS HABITANTES INÚTILES: MEDIO PARIENTES DEL DOLOR}

La ciudad de Chihuahua es el único punto del Estado donde las artes escénicas se enseñan a nivel profesional. ${ }^{11}$ También desde 1991, la Licenciatura en Teatro de la Facultad de Artes de la UACH promueve la oferta y atiende la demanda artística en ejecución, creación, gestión y docencia dramáticas. No sorprende, por tanto, que sus egresados pronto se incorporen a los circuitos y grupos ya establecidos e incluso formen sus propias compañías. ${ }^{12}$

La dramaturga, directora y actriz Valeria Loera (Chihuahua, 1993) obtuvo dicha licenciatura en 2015 y la beca de la Fundación para las Letras Mexicanas 2016-18. Sus primeros textos circulan en medios digitales; la Revista Borde publicó en 2016 el microdrama Rutinas de media noche, en donde una ruptura amaga con liquidar la desgastada relación de una pareja afecta a la costumbre; fragmentos de Auroras boreales aparecieron en marzo de 2017 en

11 Desde el año 2000, en Ciudad Juárez, se reinauguró la antigua Presidencia Municipal, ubicada en el centro histórico, como Centro Municipal de las Artes (CMA). Esta institución acredita frente a la SEP a sus estudiantes a nivel técnico (como requisito se debe contar con secundaria) en disciplinas de artes plásticas, música, danza y teatro; dentro de esta última se imparten actuación, producción, dirección y docencia.

12 Héctor Padilla concluyó hace 15 años que la coordinación de las instancias de gobierno (reguladoras de espacios y recursos), los gremios creadores y la fundación de una licenciatura en la UACJ cambiaría el panorama en la frontera, tanto en la afluencia de público, el robustecimiento de una cartelera acorde a la densidad de población, como en la fuga de recursos. "Hay indicios de un consenso dentro de la comunidad teatral favorable a la creación de programas que permitan la profesionalización del teatro, pues consideran que puede ser el factor clave que imprima un salto cualitativo a su labor; esto convertiría a la intensidad de las expresiones teatrales de la ciudad en una oferta teatral acorde a un espacio urbano de magnitud metropolitana y con la presencia de procesos que orientan en el sentido de la llamada globalización” (2005: 26). 
Este País. Midnight snack -otra pieza corta sobre la relación conflictiva entre un hombre aparentemente vació y su refrigerador, al que se ha olvidado de llenar- así como el cuadro inicial de Elefante pueden consultarse en el portal de Tierra Adentro. Debido a la complejidad emocional y el grado de experimentación formal, esta obra recibió mención honorífica en el Premio Nacional de Dramaturgia Joven Gerardo Mancebo del Castillo 2018, por lo que se imprimió ese mismo año en el volumen 18 de la prestigiosa colección de Teatro de la Gruta del Fondo Editorial Tierra Adentro. El jurado - Itzel Lara, Cutberto López y Verónica Bujeiro- encomió la desafiante mezcla de texto e imágenes, a través de una relación padre-hijo truncada por una enfermedad. La libreta de Emil sirve de soporte visual tanto para el lector como para el adulto mayor que pierde gradualmente la memoria, por lo que apunta indicaciones ("Sótano. No volver nunca aquí") y traza reminiscencias vitales sobre el plano de su casa: "Oliver es tu hijo", "Lotti es mi perro perra" (Loera, 2018: 199 y 207). El juego tipográfico, además de reforzar la trama, construye una alegoría lírica del recuerdo: Elle, personaje femenino ausente por convicción, y un paquidermo que reclama el reencuentro.

También en 2018, Valeria Loera ganó el Premio Municipal a la Juventud Agustín Melgar, por parte del Ayuntamiento de su ciudad natal. Hace un año, el Consejo editorial del municipio de Chihuahua la seleccionó, en la categoría de escritores con trayectoria, para publicar en un solo volumen Planeta Kepler o los datos inútiles y Auroras boreales o nos vemos en Alaska, prologados por la dramaturga Itzel Lara, para quien estas piezas muestran la capacidad de "retratar la naturaleza humana a través de la aparente nimiedad. Ambas giran en torno a la misma inquietud: el amor como ausencia, como un viaje solitario, como una Ítaca a la que se quiere regresar; como un destino" (2019: 13).

La dramaturgia de Valeria ha figurado en las marquesinas fronterizas gracias a un par de temporadas, primero, a finales de 2016, con el monólogo Planeta Kepler, interpretado por ella misma bajo la dirección de César Cabrera de la compañía Telón de Arena. En esta pieza, pensada como una trilogía junto con Auroras boreales, 
el ímpetu paralelo de una búsqueda y un exilio atraviesan a la protagonista. "Lo malo de viajar para olvidar es que uno se lleva consigo" (Loera, 2019: 37). Los datos inútiles, subtítulo alternativo del monólogo, sirven de mera especulación para una figura femenina que habita una pequeña habitación cercada por sus miedos (como aquel a pronunciar palabras largas y complicadas) y una cucaracha como compañera de cuarto. La segunda temporada se debe a Mario Vera y Rubén Ríos, también de Telón de Arena, quienes estrenaron en abril de 2019 De niños, c@C\#s y criaturas extrañas, un espectáculo infantil que echa mano de la danza aérea para dar cuerpo a la risa por medio de unos seres con un peculiar sentido de justicia. La coreografía montada en lo alto del edificio enmarca la peripecia de la familia protagónica que ensaya, una y otra vez, varios desenlaces hasta perpetrar el ansiando final feliz. Un texto ingenioso en su concepción, pero simple en su anécdota, se convirtió "en una experiencia creativa generadora de emociones, risas, acrobacias y un abrazo dirigido a la familia” (Márquez, 2019). En ambas piezas, los pasajes y situaciones proyectadas tienden hacia un humor agridulce y pesimista, característico de la escritura de una dramaturga en constante producción.

De acuerdo con el programa de mano entregado durante la función, Los Habitantes Inútiles, compañía fundada por Valeria en 2018, se definen como:

un colectivo joven creado por un grupo de mujeres sensibles (en el mejor y poderoso sentido de la palabra) con el mismo interés en común: compartir y convertir nuestras vivencias y experiencias personales en material potente para creaciones escénicas que representen y cumplan con nuestros ideales artísticos. [...] Quienes conformamos este colectivo nos concebimos como los "habitantes" de un espacio carente de "utilidad" como lo es el teatro, aquellos a quienes nadie va a buscar con desesperación como se busca entre las páginas de la sección amarilla a un plomero, un mecánico o un contador, aquellos individuos a los que solo se les necesita cuando lo que hay que arreglar es el alma. 
La agrupación femenina se presentó en la MET con su ópera prima: Auroras boreales o nos vemos en Alaska en el Teatro Auditorio Presidentes, en el Municipio de Saucillo. El reto para Luisa Samaniego, desde los controles en una cabina improvisada en una sala sin el equipo técnico adecuado para montaje ni climatización, fue mayúsculo. La dirección conjunta de Valeria y Diana López, también egresada de la UACH, dio vida a un par de desconocidas, Valentina y Deka (respectivamente), quienes coinciden en una estación de ferrocarril. "Después de ver una aurora boreal conocerás al amor de tu vida" dicta un proverbio japonés. El motivo del viaje hacia una zona nórdica emparenta a este particular dueto que se va develando, la una a la otra, pasajes biográficos sobre sus relaciones frustradas. Con un tono ligero y humorístico, sobre el que transcurre la interlocución, aluden temas bastante serios: depresión, sexualidad, suicidio, autopercepción, aborto y crímenes de odio contra la homosexualidad femenina. El eje rector, el amor y lo que nos cuesta hablar sobre él, componen un espectáculo lleno de luminiscencias. Tanto la serie de luces sujetas al tablado como los astros suspendidos en lo alto, enmarcan el total de acciones y evocaciones.

Valentina y Deka, con equipaje en mano, desean partir para evadirse. Mientras esperan el tren, construyen una atmósfera de intimidad y confidencia a partir de una provocación: ¿Por qué es tan difícil decir lo que sientes a los que quieres? Anécdotas, recuerdos y las instrucciones del "Manual para los corazones rotos y desesperados, guía de supervivencia básica" se suceden en una sinuosa línea cronológica, poblada por episodios entrañables, algunos más complejos que otros, pero en su mayoría desalentadores: desde la atracción que llena de vergüenza en la educación primaria, hasta la dura experiencia de un embarazo no deseado, pasando por pérdidas y rupturas sin cuento. El signo común que caracteriza a ambas biografías se concentra en el desengaño y en el miedo de empezar de nuevo.

"Me cuesta mucho escribir la palabra amor". Dicha incapacidad comunicativa da sentido y forma a las desventuras que la pareja trae a escena, sacadas desde el fondo de sus maletas (o de 
un baúl siempre en movimiento), pero también de sus ensoñaciones. La realización escénica, por tanto, recurre a distintos medios expresivos que suplen lo que la palabra en interlocución directa no logra transmitir: el nudo en la garganta, el encogimiento ante quien produce escalofríos. Lenguaje de señas, coreografías, testimonios videograbados, la proyección en diorama de un cuento tradicional japonés, la recitación del poema "Lluvia" de Juan Gelman y un soundtrack altamente significativo registran un abanico de sensaciones que surge desde la tarima y se entromete entre las filas del teatro: un olor a flores, risas, el sabor a fresa tan cercano al color carmesí con que se pinta el corazón, y la certeza de saberse enamorada tras una detenida contemplación de 13 segundos y medio.

Hacia el final de la puesta, suena la canción "A nadie", de Liliana Felipe, interpretada por Jesusa Rodríguez. La composición conjunta de esa pieza — con letra y canto al unísono- producida por la pareja de artistas abiertamente homosexual refuerza y sugiere en varias escalas lo que Deka y Valentina han aprehendido desde un ejercicio de sororidad. Si por un lado se cuestiona "Qué cosa es el amor", concluyendo de forma tajante: "medio pariente del dolor / que a ti y a mí no nos tocó”; por otra, atisban una proclama, ampliamente elaborada, pero nunca gastada y que hay que seguir cantando: "Porque no nos conocemos, / y tampoco nos queremos”. Aunque el amor nos haga vulnerables, no querernos nos vuelve inservibles. Deka insiste sobre la clave del asunto: la imagen de uno mismo, la autopercepción, procurar y aderezar nuestro ser para después -y solo si se nos da la gana- compartirnos. Al final, ella no aborda el tren; desiste de una aventura infértil, ya que el amor la aguarda en latitudes más cercanas. La obra concluye con el ruido de la locomotora sobre las vías, partiendo hacia Alaska. Desde nuestros cálidos asientos, percibimos el brillo de una aurora boreal.

A pesar de que Los Habitantes Inútiles no tuvo ningún reconocimiento en la MET, el trabajo artístico de Valeria Loera coloca a su compañía dentro de las agrupaciones estatales en formación que pronto competirán por los primeros puestos, siempre y cuan- 
do las condiciones de montaje sean las idóneas. Justo al cierre del ensayo, supimos que Valeria ganó, con su obra ¡Violencia!, el Premio Nacional de Dramaturgia Joven Gerardo Mancebo del Castillo 2020. Además de alegrarnos por el logro personal, también creemos que este tipo de distinciones posiciona a la dramaturgia en Chihuahua dentro de las mejores en la república.

\section{LA BODEGA: ALMACÉN DE LOS QUE SIGUEN (16)}

Insistimos en el impacto de la Facultad de Arte de la UACH, ya que la pericia tras la formación, el proceso de cada montaje estudiantil, en donde la intervención de la planta docente y el interés en jóvenes espectadores conforman una sinergia que beneficia al capital cultural de la ciudad. Igual que Los Habitantes Inútiles, La Bodega nació de la unión de un grupo de jóvenes de la UACH. Hace seis años, Rubén Jordán (egresado en Teatro), Víctor Velo (licenciado en Letras Españolas con la tesis La narraturgia: teatro narrativo $^{13}$ y Alberto Orozco - quien ya no pertenece a la compañía - encausaron sus proyectos individuales para abrir un Foro Alternativo, próximo a la reapertura, cuyo nombre resuena a nivel nacional.

En septiembre de 2014, La Bodega inauguró su local con la puesta en escena de Rompecabezas, dirigida por Jordán y escrita por el actor, gestor y dramaturgo de Parral, Antonio Zúñiga, quien cuenta con una amplia trayectoria tanto en las muestras estatales como en las nacionales. ${ }^{14}$ Esta pieza los catapultó desde lo local (Festival de Otoño, Muestra Municipal y MET) hasta la 36

13 La investigación, publicada como libro en la serie de Dramaturgia de la Colección Solar del ICHICULT, comprende a la narraturgia como un género híbrido (incompleto, sin una definición clara y existente desde hace siglos) que deambula entre la narración y la dramaturgia. Velo asegura que este tipo de "teatro narrativo hecho para leerse y no para representarse" rompe con la estructura misma del teatro, ya que su fin último consiste en la "representación en vivo donde el espectador pueda estar atento a lo que ocurre con la palabra” (2015: 143 y 145). Es decir, lo central del arte dramático recae en la acción y no en la palabra.

14 Tomóchic, dirigida por Octavio Trías, con dramaturgia y actuación de Joaquín Cosío y Zúñiga, del Taller de Teatro Experimental de la UACJ triunfó en la XIII MNT (1992), en Monterrey (Partida Tayzan, 2008: 45). 
MNT, en Aguascalientes (2015), donde se montó en la categoría de Teatro de Nuevos Creadores y Teatro Universitario. El éxito de su ópera prima cubrió un par de temporadas más en foros independientes, beneficiados con el programa México en Escena: primero en la Sala Subterráneo, de Teatro Bárbaro, en el Centro histórico de Chihuahua; luego en el Centro Cultural Carretera 45, en la Ciudad de México. Su segunda producción, Precisiones para entender aquella tarde, de Hugo Wirth, se estrenó en octubre de 2015 en el foro de Teatro Bárbaro, compañía con la que colaboran e interactúan con frecuencia. Gracias a este montaje, durante la Muestra Municipal de Chihuahua del 2017, Víctor Velo, actual productor y director de relaciones públicas y logística de la agrupación, obtuvo el reconocimiento como Mejor Actor. Además, ese mismo verano, la obra formó parte de la caravana del FICH.

La Bodega ejemplifica la proyección obtenida a partir de una serie de conexiones - nacionales, locales, institucionales e incluso afectivas- dentro del mundo teatral. En 2014, por ejemplo, Alejandro Ricaño obtuvo Mención Honorífica en el Premio Nacional de Dramaturgia Manuel Herrera Castañeda por Esa melancolía que le da a uno a veces; dos años más tarde, le cedió el texto a La Bodega para que lo montaran. El estreno sucedió en el foro de Teatro Bárbaro; luego se convocó para cerrar el Festival de Teatro de la Ciudad; en el 2017 se presentó en el Teatro La Capilla de la Ciudad de México y, finalmente, participó en la 26 MET, llevada a cabo en Ciudad Juárez.

Antes de adentrarnos en el montaje con el que La Bodega participó por tercera vez en la MET, destacamos el resto de sus producciones y reconocimientos. Velo posee una sólida trayectoria como dramaturgo que lo ha llevado a ser finalista del Premio Nacional de Joven Dramaturgia Gerardo Mancebo del Castillo, en el 2017 con El hombre que escuchaba baladas de Alejandra Guzmán y, un año después con Dislocado, publicadas en Teatro de la Gruta XVII y XVIII, respectivamente. Asimismo, representó a México en el Circuito Internacional de Joven Dirección y Dramaturgia 20182019 con Goma 2-ECO; hace tres meses ganó el Premio Nacional de Dramaturgia Joven Teatro Sin Paredes gracias a No tengo los 
huevos (2019). En el 2017, bajo la dirección de Rubén Jordán, La Bodega estrenó Poquito, texto de Velo que recorrió varios municipios al formar parte del programa Red de Teatros e integrarse al FICH. En 2018, con la dirección escénica de Romeos, escrita por Zúñiga, Jordán obtuvo el estímulo de Creación Artística Colectiva por parte del Fondo Municipal para Artistas y Creadores (FomAC). Ese mismo año participó como becario en la 39 MNT, así como en el programa de Jóvenes Creadores del FoncA con el proyecto Tsuru-Tespís. En 2019, obtuvo recursos del mismo fondo para producir El hombre que escuchaba baladas de Alejandra Guzmán, escrita por su colega, Víctor Velo.

La Bodega puso en marcha en 2016 el proyecto Soy Bernarda Alba, gracias al Programa de Estímulos a la Creación y el Desarrollo Artístico (PECDA), con lo que lograron estrenar en mayo del año siguiente; y luego, ser seleccionados para la $28 \mathrm{MET}$, obteniendo solo un reconocimiento, Mejor Iluminación, a pesar del gran trabajo actoral del elenco femenino, sobre todo de la licenciada en teatro, Melissa Baca. En el espacio del escenario (la gradería en proscenio de cara al fondo) del teatro principal en Delicias, cinco actrices recrearon el drama insignia de Federico García Lorca: La casa de Bernarda Alba, escrito en 1936. Una mesa en forma de herradura, ocupada por unos cuantos espectadores, funcionó como foco de acción para desarrollar una historia de represión/ sublevación. Bajo el mandato de su madre, Angustias (Georgina Ayub), Magdalena (Diana López, de Los Habitantes Inútiles), Amelia (Nancy Gardea), Martirio (Flor Hernández) y Adela (Melissa Baca) habitan un mundo íntimo plagado de deseos, encierro, celos e intrigas. La casa se cimbra con la muerte del segundo esposo de Bernarda, pero parece venirse abajo con la llegada de un inconveniente: Pepe el Romano.

El reconocimiento más que merecido que obtuvo La Bodega por su plano de iluminación fue diseñado por Héctor García Ortega ("Magnum", de Teatro Bárbaro), a cargo también de la escenografía y tramoya. El ambiente lúgubre de la casa se percibe a través de una tenue, pero cálida luz, tanto en lo alto, como con las velas sobre la mesa. Acondicionadas con focos suspendidos, 
las luces transmiten un ansia que titila, inquieta, parpadea y que pocas veces irradia armonía.

La mayoría de las adaptaciones de la pieza del granadino se basan en la tajante distancia que Bernarda, en un rol masculino, pretende imponer entre la familia y el pueblo. No obstante, la versión dirigida por Rubén Jordán invade la privacidad del hogar con la intromisión del público, con quienes las protagonistas departen alimentos. Este giro se concentra en el accionar del poder, en su desbordamiento encarnado por cada residente. De ahí el ajuste al título y la descripción del montaje: "Una deconstrucción a partir del texto clásico”. Todas son, en algún momento, Bernarda Alba. Aunque las palabras del afamado dramaturgo se mantienen intactas (salvo mínimos cortes), la ruptura entre el espacio interior/ exterior se transforma en equivalencia y representación del juego de coerciones. Es decir, en la propuesta de La Bodega, la vida privada y pública convergen en una mesa, demostrando que no existe un lugar - a pesar de que solo lo habiten figuras femeninas- libre de las secuelas del poder estructural - patriarcal- que rige nuestra sociedad. En esta línea, la conocida frase feminista "Lo íntimo-privado es político" cobra aparejo y sentido.

Como ejemplo, recurrimos a la escena en donde el asesinato tumultuoso de la hija de Librada, madre soltera que mata a su hijo para ocultar su deshonra, recae en el cuerpo de Adela. La menor de la familia se identifica de inmediato con la desdicha, pues asume las consecuencias de enredarse con el prometido de Angustias. Un suceso extramuros potencia su brutalidad a través de las súplicas de Adela, y, sobre todo, cuando sus hermanas la bañan con agua de jamaica, que acompañaba los alimentos y que, súbitamente, simula la sangre de las promiscuas sentenciadas. Este cuadro conjuga la estética de la propuesta; es decir, el furor de la violencia machista - la cual permea en la mujer víctima y victimaria - se ejecuta a partir de símbolos y acciones que, si bien por momentos aturden (los gritos de Bernarda o la voz de la abuela que hace vibrar el inmueble), son parte de una cena familiar cotidiana, en la que los cubiertos, en especial los cuchillos, amedrentan y el agua fresca ahoga. Ante estas soluciones impac- 
tantes que transgreden los referentes inmediatos, consideramos que el contacto físico, manifestación primaria y burda de la violencia -aunque duró solo unos instantes en las últimas escenasdesentona con una atmósfera tan sugerente.

En Soy Bernarda Alba, la omnipotencia de la madre se desdobla en sus hijas. Un boxer de acero en los nudillos de las actrices marca el cambio del personaje. Lo mismo ocurre con una servilleta al hombro cuando enuncian los diálogos de las criadas. Sin embargo, la claridad de estos cambios radica en el arte histriónico del elenco. Las cinco hermanas coprotagonistas exhiben cómo el poder sobrevive solo cuando los subyugados no cuestionan. A partir de la cimentación de estos personajes, cada actriz extiende la personalidad de la mujer que ha corporizado en la construcción de sus Bernardas, Poncias o Prudencias.

Todas, en algún momento, somos Bernarda Alba y, cuando no, consentimos su existencia; participamos de un mismo problema, encarnando distintos roles. La puesta de La Bodega pugna por romper esos estigmas. Más allá del claroscuro aludido en el texto dramático, el vestuario evoca rupturas de la moda femenina con las tradiciones impuestas en distintas épocas. Adela representa la liberación sexual, y es la única en llevarla a sus últimas consecuencias: "Dichosa ella mil veces que lo pudo tener" (García Lorca, 2008: 66), afirma Milagros ante el cadáver de su hermana; evolución y rebeldía que percibimos con sus cambios de atuendo: pantalón oscuro y camisa clara, tirantes, un vestido verde, el referente al grupo The Runaways, y la bata blanca con la que muere. Adela transgredió las reglas de su sociedad y familia; pese a ello, su última aparición refiere a un halo de pureza, a un nuevo amanecer en donde todas podamos ser Alba a partir y pese a nuestras decisiones.

\section{TEATRO NORTE: EL LEGADO DE UNA CONCIENCIA SOCIAL}

Al inicio de la centuria, Edeberto "Pilo" Galindo veía a su comunidad teatral, la fronteriza, como "la más envidiosa y autodestructiva [incapaz] de coexistir en un mismo espacio y tiempo [...]. Cuando 
alguien tiene éxito lo odian. Esa es la gran debilidad del teatro en Juárez" (Padilla, 2005: 190). A pesar de la competencia desleal, su compañía, junto con otras de igual longevidad y trascendencia, como Telón de Arena, así como la constante emergencia de talentos y agrupaciones, han hecho del teatro de frontera un hito. ${ }^{15}$

En 1986, el ahora reconocido director y dramaturgo juarense fundó el Taller de Teatro Experimental 1939, dedicado, desde entonces, a la producción y promoción de espectáculos escénicos, en su mayoría de raigambre social. Un año después, el Auditorio Cívico Benito Juárez recibió a El indolente, primer montaje escrito y dirigido por Pilo (como lo conocemos), con ayuda de Octavio Trías. Respecto a esta emblemática figura de la escena chihuahuense, Galindo lo posiciona como un parteaguas de la escena, precursor directo de su estética; a finales de los 80, "moría también el viejo estilo psicodélico [...] y se emprendía un éxodo hacia la búsqueda de formas más nítidas y simples" para tratar temas comunes; "se renunciaba a lo excepcional para abocarse a lo ordinario; se abandonaba lo cósmico y se privilegiaba lo mundano”. El teatro realista de Trías, con violencia y furor, pero también de compromiso, "marcaba pautas, refutando moralismos con audaces escenas que en clara irreverencia retaban la 'ortodoxia' de los teatristas más viejos. Lo urbano rebasaba la concepción espiritual de los conflictos humanos" (Padilla, 2005: 190-191). Menos forma y más víscera, concluye Pilo frente a la cámara de Luis Sierra (2005).

La agrupación estrenó en 1988 Amor... ¿propiedad de quién? en el Festival de Otoño, organizado por el INBA y el municipio. Al año siguiente montó El bufón y Los otros márgenes. En 1990, antes de que la MET se pusiera en marcha, 1939 participó en el Festival de Primavera con El Zurdo, pieza que subió a las tablas a un grupo marginado - los cholos- para performar sus actitudes, caló y vestuario. La variedad en las carteleras "provocó euforia en un movimiento teatral, que comenzó a llenar las salas de público genuino”. La pujanza entre compañías, recuerda Pilo,

15 Véase el trabajo de Margarita Salazar para comprender los detonantes de la escritura en Ciudad Juárez (2010: 139-165). 
...obligó a que las autoridades culturales, que antes designaban al grupo de teatro [se refiere a la Compañía de Teatro del Gobierno del Estado] por 10 años consecutivos para asistir a la muestra nacional de teatro organizada con el CNCA, llevaran a cabo una muestra estatal de teatro para seleccionar uno o dos grupos para representar a Chihuahua en el evento nacional. El Zurdo, obra local, fue la primera en acudir a este evento. A partir de ahí, Ciudad Juárez comenzó a ocupar un lugar en el teatro nacional (Padilla, 2005: 191).

Aunque el grupo universitario de Ochoa Guillemard fue el primero en asistir a la Nacional, hay que reconocer el éxito y proyección de El Zurdo en la XI MNT, en Monterrey, que le valió una gira por Noruega, Argentina, Nueva Delhi, España y Estados Unidos. En la segunda MET, concursó con Dios en disputa, la cual también alcanzó la Nacional, la XII, en Aguascalientes (Padilla, 2005: 244-245). Desde entonces, 1939 se ha posicionado como una de las productoras de artes escénicas más representativas del Estado. Los galardones del dramaturgo juarense - sin contar los múltiples reconocimientos locales, así como becas estatales y preseas en las MET- lo ubican en la primera fila del teatro nacional. ${ }^{16}$ No sorprende que su escritura nutra las carteleras a lo largo y ancho del continente. ${ }^{17}$

En 2013, 1939 Teatro Norte se constituyó como Asociación Civil. Aunque Pilo continúa al frente, sobre todo con su dramaturgia, existe una notable apertura a nuevas direcciones, voces y actuaciones. Debido a este talante se creó en 2016 como grupo afiliado, el Movimiento OT Teatro Lab -en honor a Octavio Trías- para obtener una mayor perspectiva y proyección escénicas. El caimán y los sapos, dirigida por Abraxas Trías (hijo de Octavio), fue la

16 2002: Premio Chihuahua de Literatura por Lomas de Poleo (morir con las alas plegadas); 2003: Certamen Nacional de Pastorelas por Diablo a la diabla; 2005: Premio Nacional de Dramaturgia por El diputado; 2007: Premio Nacional de Dramaturgia por La furia de los Mansos; 2015: Premio de Dramaturgia Juan Ruiz de Alarcón, por trayectoria.

17 Desde el estreno de Curva peligrosa (2007), no ha habido año que esta obra, impresa en los Cuadernos de Dramaturgia para Joven Público de la editorial Paso de Gato y perteneciente al Programa Nacional de Teatro Escolar, sea montada en algún punto de la República o en Latinoamérica. 
Mejor Obra de la MET pasada, por lo que accedió a la Regional de Teatro Noreste, en Tamaulipas; en el 37 Festival de Teatro de la Ciudad, en Juárez, obtuvo el tercer lugar y Laura Galindo (hija de Pilo) se galardonó como Mejor Actriz. ${ }^{18}$ En este mismo evento, Millenials ganó como Mejor Obra, Director (Pilo), Actriz y Actor Revelación. A fines del año pasado, el actor David Vázquez estrenó su ópera prima al frente del monólogo Eunucos, emulando la trayectoria de Laura Galindo como directora. ${ }^{19}$

Cada premio o mención representa el esfuerzo de 1939 Teatro Norte por mantener vivo, durante más de tres décadas, un arte que enfrenta un sinfín de obstáculos en el contexto cultural de nuestra frontera. Sus producciones crean espacios y oportunidades, ya sea desde las tablas o entre las butacas, para una sociedad vulnerada; desde el escenario, sacuden conciencias con historias que mueven los hilos de los distintos vínculos -familiares, fraternales o comunales- con los que actuamos fuera de las ficciones. Así lo demuestra el par de piezas que presentaron en la MET 28, sobre las que ahondaremos a continuación.

En el segundo día de actividades de la MET, el escenario del Teatro Camargo se revistió con el acomodo y diseño de las conferencias trasnacionales TED: enormes letras rojas (\#MLNS) y una alfombra circular carmesí al centro. Bajo el lema "Ideas que merece la pena difundir", surgió en 1984 la plataforma donde cientos de motivadores e influencers ofrecen charlas exprés sobre experiencias de éxito. En esa misma década apareció la generación que le da nombre a la más reciente obra de Pilo Galindo, aquellos que se hicieron adultos junto con el cambio del milenio. La referencia a las TED Talks remite a un mundo "salvajemente práctico". Bastan 18 minutos para exponer una historia, frente a un público cautivo, que se hará viral en YouTube, hasta que aparezca dos días des-

18 Resaltamos los lazos familiares para rastrear el devenir de una agrupación que, más allá de lo sanguíneo, hereda preocupaciones temáticas y resoluciones escénicas. En octubre del año pasado, se estrenó, primero como lectura en atril, y posteriormente como montaje Los invisibles, escrita por Pilo y protagonizada por el pequeño Octavio Trías Galindo, hijo de Laura y de Abraxas. Si existe un cromosoma teatral, este niño porta varios.

19 Así lo ha hecho en Bubble gum, En un tren militar (ambas escritas por Pilo) y en tres cuadros de la obra colectiva Mexicanas de Telón de Arena, dirigida por Alan Posada. 
pués una nueva videoconferencia; sin embargo, nuestros límites o lapsos de atención favorecen contenidos claros, de fácil resolución y en formatos preestablecidos. Millenials, de 1939 Teatro Norte, explora, en primer término, los beneficios de esta cadena de producción-consumo en entornos virtuales, para después defender los discursos emergentes, en pro de un mundo mejor, enunciados por una juventud denostada por una mirada adultocéntrica.

Las principales peculiaridades de los millenials residen en el uso de la tecnología, casi como prolongación de su cuerpo, la sobrepreparación académica - lo cual dificulta la obtención de empleo- y una mentalidad abierta, en cuanto a relaciones personales y diversidad sexual. Todo ello aparece en Millenials o de cómo vivir solo entre tanta gente que, a la postre, obtuvo el reconocimiento como Mejor Dramaturgia Original y posicionó a Estefanía Estrada como Mejor Actriz en la MET 28. Hemos presenciado este montaje tres o cuatro veces en diferentes foros y con públicos diversos; nos hemos cuestionado sobre el espectador ideal a quien se dirige, ya que, para nuestra sorpresa, siempre ha habido un sector de la audiencia que se conmueve, se entrega a los chistes y aplaude con estrépito al final.

Notamos inconsistencia entre el ser y proceder de los protagonistas, Adiel Cohelo (Christian Valenzuela) e Icaichi. Por ejemplo, desde el comienzo se dice que ambos concluyeron posgrados -él en Mercadotecnia, ella en Relaciones Internacionales-, además de varios diplomados, lo cual los limita laboralmente. Tal situación se ajusta a la crítica presente en la dramaturgia: "Somos la generación más informada”, enuncian ambos en la reflexión postrera. Sin embargo, la personalidad y el conocimiento de Icaichi no coinciden con la preparación que ostenta. Aunque un título académico no es carta abierta a los referentes culturales, la joven desconoce al escritor Julio Cortázar y a los directores Perla de la Rosa y Luis Bizarro. Por tanto, el saber a través de las aplicaciones tecnológicas depende, no de los likes o de los trending topics, sino de un gusto e interés genuinos. Esta dicotomía no se dilucida en el montaje; ¿ironiza la desvalorización de los jóvenes, o la incongruencia define a los millenials? Más comentarios y burlas en 
torno a graves problemáticas: contaminación del medio ambiente (el popote y la tortuga), guerras (entre Túnez y Siria), depresión y lenguaje inclusivo (el stand up "La hije de la luna") abonan a desestabilizar la respuesta.

La puesta en escena nos invita a preguntarnos cuál es la manera de enfrentarnos y nombrar a estas situaciones, herencia de años de indiferencia hacia la naturaleza y la misma condición humana; cuál, nuestra responsabilidad desde el ámbito artístico para cambiar "este pinche mundo". Sin duda, Millenials rescata acciones positivas de la generación: limpia de ecosistemas, respuesta inmediata al terremoto de la Ciudad de México de 2017, marchas feministas, consignas a favor de la diversidad sexual. No obstante, el montaje sucumbe ante la ambigüedad de la broma, ante la dificultad de desentrañar una postura aún inestable, una indeterminación inmanente que la audiencia juvenil celebra y no duda en ovacionar de pie. Las tecnologías remotas sirven como medios para resguardar nuestro pedazo de planeta; sin embargo, ¿qué tanto dependemos del recurso? ¿Cómo soluciona un espectáculo multimedia las fallas eléctricas del proyector? ¿El activismo dura lo mismo que la batería del celular?

El penúltimo día la muestra, el Teatro Manuel Talavera, en Delicias, cedió su foro a una ambientación — sonora y cromáticareferente a la inmensidad del espacio sideral. Filos escenifica un tema esencial en las relaciones sociales, la amistad, en un momento donde pareciera que toda transacción depende del capital monetario. Movimiento OT Teatro Lab la estrenó con una triple dirección colectiva (de los mismos intérpretes) en marzo de 2018 en el local de Telón de Arena. ${ }^{20}$ La acción comienza con Lenin (Abraxas Trías) a punto de suicidarse bajo una mesa enmarcada con luz de neón. De fondo suena "Vaquero galáctico", de la banda

20 Ese mismo año, obtuvieron el segundo lugar en el Festival de Teatro de la Ciudad; en septiembre, se fueron de gira por varios municipios en las caravanas del FICH. También la montaron en Nuevo León y en el Primer Festival de Teatro Itinerante en Mérida. El texto, original del fundador de 1939, aparece en el primer volumen de su Antología teatral (Galindo, 2016: 172-207). Filos ya había sido montada en Juárez por otras compañías locales, en la capital —donde forma parte del repertorio de Teatro Bárbaro-, en Querétaro y Bogotá. 
de rock Porter: "Me despierto en mi nave tras mil años luz / y me faltan varios. / Voy por un vaso de mis orines filtrados, / bebiendo me siento en la proa y veo al espacio". Si bien la letra presagia un tono melancólico, Benito (Christian Valenzuela) entra y descubre a su amigo intentando emborracharse con jugo de manzana y acercarse al "filo de la muerte" con una pistola de plástico. Entonces, entablan un diálogo hilarante y lúdico, sostenido entre camaradas que se fastidian sin tregua, pero sin dolo, convivencia vital para uno y otro.

En las primeras escenas, Lenin luce con mayor dominio sobre el "pinche Benito", pero ciertos incidentes (como quebrar una botella de vino) van sembrando la duda. Después de que la bella Irene (Laura Galindo), ataviada con un sensual vestido, le enseña a bailar a Lenin y lo incita a besarla, es decir, aproximarse al "filo de la felicidad", la verdad comienza a revelarse. Los indicios van tomando cuerpo en el accionar de Lenin: le tiembla una pierna, tartamudea. La discapacidad se manifiesta, así como el significado del montaje: "El amor tiene dos filos... Uno de ellos corta, hiere, lastima... El otro te salva” (Galindo, 2016: 196), le explica Irene al enamorado e ingenuo Lenin.

Ante la enfermedad motriz, la imaginación y recreación de universos alternos resultan una vía de asimilación y aceptación, asistida por la compañía, el amor y la paciencia de Benito. Sobre este escape, diseñado para confortar al entrañable amigo de secundaria, se construye la obra, pues la representación de una falsa realidad lo pone al borde de situaciones y tomas de decisión concernientes a la propia idea de hermandad. ¿Cómo apoyar al amigo en un escenario tan adverso? Filos responde: imaginando que no es tan complicado, hacer de los retos un juego, de la terapia un pasatiempo, de los insultos una conexión filial, aun cuando ambos conocen la realidad y que su amistad roza "el filo de la verdad".

Este mecanismo de reconversión del infortunio se refuerza por un dispositivo escénico compuesto por elementos que incitan al vuelo de la imaginación: luces con tonalidades celestes, el mobiliario ilustrado con una nave espacial, el repertorio musical, las piñatas y las referencias a videojuegos en el vestuario. Además 
de la belleza de la figura femenina, Irene se suma con su interés y empatía hacia el par de amigos. A quienes conocen la trayectoria de los histriones y directores, se les revela una fuerza visceral y emocional mayor, debido al lazo fraternal que une a su laboratorio escénico. Filos aboga por nuevas y necesarias formas de convivio, aquellas basadas en el acogimiento, la solidaridad y el cariño. Así, aunque nuestra nave se averíe, como señala la canción "Love" del grupo Zoé con la que culmina la función, nuestra tripulación seguirá intacta.

\section{TELÓN DE ARENA: TEATRO DE/SIN FRONTERAS}

En octubre de 2002, un grupo de creadores radicados en Ciudad Juárez se constituyó como asociación civil con el objetivo de producir y promover espectáculos escénicos. Casi dos décadas después, Telón de Arena se configura como una de las compañías más sólidas del norte de México a través de la capacitación de su nutrido elenco, gestión de recursos, activación de espacios, giras, festivales y vinculación con su comunidad. Durante los primeros nueve años, administró el Teatro de la Nación (del IMSS) con proyectos comunitarios y escolares. En 2011 recibió el apoyo del programa México en Escena de la Secretaría de Cultura y del FoncA, el cual ha logrado renovar. Gracias a dicho estímulo, Telón de Arena realiza múltiples proyectos para formar públicos "específicamente para el teatro, como una manera de ayudar, desde el campo de la cultura, a revertir en Ciudad Juárez los síntomas de la descomposición o deterioro de dicho tejido social" (Padilla y De la Mora: 219). ${ }^{21}$

21 No nos detenemos en la historia del grupo fronterizo, ya que varios textos dan cuenta de ella. Los antecedentes de su fundación se encuentran en Telón de voces (Padilla, 2005). De igual forma, su cometido social y escénico, así como los reconocimientos hasta 2010, se detallan en el artículo "La reconstrucción del tejido social desde la cultura. El caso de Telón de Arena en Ciudad Juárez” (2011). Por su parte, Perla de la Rosa ahonda en la quintaesencia de su compañía en "Justica negada: el teatro como acción solidaria” (2016). Además, la revista Paso de Gato le dedicó un dossier en 2018, al perfil de la cofundadora, directora, dramaturga y afamada actriz. Los artículos de Brisa Frías, Patricia Ariza, Luisa Huertas y Joaquín Cosío detallan la experiencia teatral (de cuatro décadas) de Perla de la Rosa y, por tanto, de Telón de Arena. 
Desde su fundación, Telón ha participado, con grandes resultados, en la MET. Bernarda Alba, la potestad del cuerpo, versión y dirección de Perla de la Rosa (Sistema Nacional de Creadores de Arte 2018-20), recibió el primer galardón como Mejor Obra del naciente grupo en 2002. Cinco años después, Contrabando (aún en repertorio) obtuvo ese mismo reconocimiento, además de Mejor Escenografía a César Cabrera y Mejor actriz a Guadalupe de la Mora, pilares actuales de la compañía. Comala (2010), Generación Nini (2014), dirigida por Cabrera y Deconstrucciones o de cómo enterrar sin escarbar (2017), por Alan Posada, también se posicionaron como las mejores puestas en escena del Estado.

Hoy en día, Telón cuenta con 68 producciones dirigidas por distintos colaboradores, de las cuales 23 se mantienen en repertorio. Entre las más representativas, amén de las ya mencionadas, destacan Safari en Juárez (2016), cuya dirección artística estuvo a cargo de Adelheid Roosen y Daniel Giménez Cacho, y la escénica de Raúl Briones, Titus Muizelar y Perla de la Rosa; Los muertos (2015) dirigida por Sebastien Lange, con un elenco fluctuante en cada temporada; Desorden público (2018) e Intervenciones (2019) dirigidas por César Cabrera; El enemigo (2011), Justicia negada (2013), La Celestina (2015), Fuente Ovejuna (2017), Río Animas (2017) y La señora Macbeth (2018), bajo la dirección de Perla de la Rosa; entre otras que les han permitido realizar once giras nacionales e internacionales.

Aquí no es (en realidad, no hay) el espacio para detenernos en las distinciones ganadas en conjunto o por los más de cuarenta creativos, actores, técnicos, músicos y equipo de apoyo que actualmente laboran en Telón de Arena. Añadimos, sin embargo, que su Café-Teatro, inaugurado en mayo de 2013, mantiene una cartelera permanente de martes a domingo con estadísticas impresionantes: más de mil seiscientos eventos para cerca de 73 mil espectadores de todas las edades. La autogestión de su espacio permite recibir a grupos invitados que diversifican la oferta cultural en la ciudad, así como implementar talleres, seminarios, presentaciones de libros o salas de lectura. El Laboratorio Escénico Teatro de Fronteras, por ejemplo, materializa las experiencias de 
intercambio, el trabajo interdisciplinario y el desarrollo de óperas primas de jóvenes directores.

Además de los logros artísticos, Telón destaca por una labor sostenida en el tiempo y que, en cada producción, se cuestiona las posibilidades y responsabilidad de su quehacer. En un panorama de inhumanidad, cruzado por los ejes más atroces de la violencia global: narcotráfico, feminicidio, explotación sexual, trata de personas y migración, el mejor espectáculo dramático sería aquel que "intentara ser solidario con las víctimas, un teatro como una voz y un rostro que rompiera el silencio, que visibilizara la atrocidad más allá de las cifras que esconden la dimensión real de la muerte" (De la Rosa, 2016: 13).

Telón de Arena participó en la MET 28 con un par de montajes, muestra de su compromiso social, sello característico del teatro de frontera, preocupado por lo regional con resonancias y lecciones más allá de Ciudad Juárez-El Paso. El Teatro de la Ciudad de Camargo se enfrentó al reto que implica montar King Tiger fuera del espacio para el que fue concebida. Un corredor, tipo pasarela sobre el escenario principal, enmarcó los espacios en donde se desarrolla, por casi dos horas, la biografía de Reies López Tijerina. A pesar de algunos titubeos técnicos —en iluminación, video y sonido-, la fiereza en la voz y aplomo del protagonista (Jorge Rodallegas), así como la intervención de su familia (Guadalupe de la Mora, Gisela González y Jesús Piña), equipo de campaña (Mario Vera, Roberto Beltrán), el reportero (Benjamín Duarte) y el magistral (Humberto Leal) revelaron una historia desconocida para la mayoría de quienes ocupamos las graderías, también sobre las tablas. Asimismo, el vestuario (ganador de esa categoría, diseñado por Guadalupe de la Mora) y los demás elementos escenotécnicos (enormes mantas con consignas de "La voz de la justicia", máquinas de escribir, fotografías reveladas en luz roja, una maqueta a escala, y todos los props vintage) lograron inmiscuir al espectador en un contexto sacudido por la lucha social de las comunidades hispanas en el suroeste norteamericano.

¿Quién fue King Tiger? ¿Cómo se ganó el apelativo? ¿Por qué su imagen ha sido borrada de la historia oficial? El montaje, estre- 
nado en marzo de 2019, rememora a un controvertido activista de los años 60 que luchó sin tregua por la tierra ("las mercedes") y los derechos de quienes, hasta hoy, son minimizados por los "americanos": latinos, hispanos, chicanos, mexicanos, greasers, beaners... los otros. Reies López Tijerina, nacido en 1926 en Texas, recogió sus memorias en Mi lucha por la tierra, con el afán de que "ningún extranjero interpretara mi vida y mi lucha porque lo harían con una mentalidad de títere, al servicio de sus patrones" (1978: 302). A partir de la autobiografía, investigación hemerográfica, fotografías, estudios académicos y una entrevista al mismo Tijerina durante sus últimos días en Ciudad Juárez, el cineasta Ángel Estrada grabó el documental Me llamaban King Tiger (2017), el cual fungió como base para la dramaturgia de Perla de la Rosa. ${ }^{22}$

King Tiger construye a un rebelde en el corazón del imperio (subtítulo de la obra) uniendo y contraponiendo su vida política y personal, alrededor de los temas que lo aquejaban: religión, familia, justicia, identidad. En el juicio, una vez expuestas las anécdotas, sueños, visiones y acusaciones, el veredicto recae en el público, que sopesará el valor de la sangre, la raza, la libertad y el derecho. La toma de decisión, tras presenciar el trasfondo de los actos políticos de un hombre radical y creyente - tanto de lo divino como de lo humano- nos conflictúa. Cuando King Tiger, apelativo acuñado por la prensa, nos insta a: "Que dé un paso al frente todo aquel que esté dispuesto a dar su vida por la lucha", pocos se levantaron. "Todos los demás son los primeros que deberíamos pasar por las armas, porque son los primeros que van a traicionarnos". Nosotros dudamos.

La copresencia de actores y espectadores en un mismo plano potencia el vínculo de lo estético con la esfera política. El público se vuelve testigo directo (cara a cara) de las declaratorias de la esposa e hijos de López Tijerina; atestigua su renacimiento; tiembla con ellos durante el atentado; forma parte de los sueños del predicador; es cuestionado sobre su historia nacional y, por

22 Otro intento desde el drama por rescatar a la emblemática figura al frente de la lucha por los derechos civiles y humanos de los hispanos en EE. UU. es la pieza Tigre de tierra amarilla (2015) de la escritora Selfa Chew. 
último, asume el litigio, con toda su carga ética-moral, desde el estrado (en una escena extensa que no precisa síntesis). Si bien este recurso resulta típico del arte teatral, el encuentro, confrontación e interacción en King Tiger invitan a cuestionar nuestra responsabilidad al momento de calificar decisiones ajenas y valores tradicionales o conceptualizar una idea operativa de justicia. ¿Qué sacrificaríamos para alcanzarla? Perla de la Rosa escenifica dicotomías ideológicas a través de la estampa de quien estuvo dispuesto a asumir las consecuencias (exiliarse, envejecer solo y pobre) de enfrentarse a un poder inmisericorde. Nuestro trabajo como comunidad consiste ahora, en incorporar aquellas biografías marginadas, controversiales, al acervo histórico de una región transfronteriza, como un mínimo acto de reposición de justicia.

A la orilla del río se estrenó en Múnich durante una gira por varias ciudades alemanas, en mayo de 2019; dos meses después, se presentó en Juárez en el 37 Festival de Teatro de la Ciudad. Con esta pieza se clausuró la MET 28 en el Teatro Manuel Talavera, en Delicias, y Perla de la Rosa se alzó con la Mejor Dirección, convirtiéndose en la obra suplente.

La experiencia migratoria en la puesta en escena se construye desde una coordenada geográfica -el antiguo Paso del Nortecon una tradición de cruce más antigua que las naciones limítrofes, una frontera vapuleada por impulsos mediáticos, alguna vez conceptualizada por la prensa norteamericana como "laboratorio del futuro", pero que aloja a residentes estables, habitantes que de uno u otro lado practican su ciudadanía en dependencia completa de las dinámicas fronterizas. La convivencia cotidiana entre economías de primer y tercer mundo exhibe la asimetría entre el municipio chihuahuense y el condado texano. Una misma región metropolitana, compuesta por dos núcleos urbanos más sus respectivos contornos, dicta el devenir de los que alguna vez arribaron -quizá para cruzar al otro lado (no siempre de sur a norte) o para alcanzar la otra orilla continental-, y en Ciudad Juárez o El Paso echaron raíces. Con el transcurrir de las generaciones, sus descendientes quizá olvidaron el signo nómada de su estadía; no obstante, un vistazo al archivo familiar o la consulta documental 
develan que la memoria e historia de esta zona están marcadas tanto por el tránsito (puesto en pausa unas cuantas décadas), como por el flujo constante (detenido hasta que el nieto lo decida) de personas.

El reparto de A la orilla del río (Humberto Leal, Guadalupe Balderrama, Mario Vera, Claudia Rivera, Rubén Ríos y Gisela González, como actriz y asistente de dirección) asume el resultado de la pesquisa histórica y hemerográfica para recrear momentos álgidos de la frontera - algunos de hace más de un siglo, pero otros (como el que le da identidad visual al montaje) sumamente cercanos-; estos acontecimientos repercuten en la biografía del elenco, por lo que el recurso del biodrama se entrelaza con el mismo ecosistema binacional, acotado por una demarcación con aras de ser infranqueable, pero que siempre ha sido porosa.

En el talud del río Bravo, cerca del Puente Internacional Paso del Norte, se celebra un particular encuentro desde 2016: Abrazos no Muros \#HugsNotWalls, organizado cada mayo por la Red Fronteriza de los Derechos Humanos (con sede en El Paso). El evento congrega a centenares de familias, separadas debido a su estatus migratorio, para que un exiguo abrazo de cinco minutos funda sus cuerpos tras años sin contacto presencial. La política exterior de Trump endureció el resguardo de su frontera sur; recortó fondos de cooperación binacional y, en atención a su promesa de campaña, levantó un nuevo muro en la zona urbana, sustituyendo la malla ciclónica. Abrazos no Muros de 2018 se anunció como el último. Ante la cancelación, colectivos artísticos y asociaciones activistas alzaron la voz y protestaron, cada uno desde sus trincheras. Justo cuando se hubiera celebrado el evento del año pasado, Telón de Arena estrenó $A$ la orilla del río, con el subtítulo de \#HugsNotWalls y un diseño gráfico en el que dos gigantes, sobre el vado, se abrazan; el muro y las torres de control no alcanzan, siquiera, sus rodillas.

La obra incorpora a su dramaturgia referencias musicales, poéticas, teatrales, periodísticas, fotográficas y documentales, a veces difíciles de identificar, por lo que el programa de mano debería discernir entre lo propio, las notas de inspiración y la cita textual. 
El mosaico de referencias es exponencial; llama la atención que la directora intercale famosas expresiones latinoamericanas, como versos de Eduardo Galeano o del grupo Calle 13, con manifestaciones locales: Moriré en el río (1979), canción compuesta por Beto Lozano e interpretada por Los Silver; El viaje de los cantores (1989) de Hugo Salcedo; Pez al cielo (1995) de Ricardo Morales; El tiradito: crónica de un santo pecador (2003) de Antonio Zúñiga; Ringside Seat to a Revolution: An Underground Cultural History of El Paso and Juárez, 1893-1923 (2005) de David Dorado Romo; Te diría que fuéramos al Río Bravo a llorar pero debes saber que ya no hay río ni llanto (2013) de Jorge Humberto Chávez; la desgarradora crónica periodística "Nohemí, el suicidio de una niña migrante ecuatoriana" (2017) de Marco Antonio López, entre otras que seguro desconocemos.

Para que este collage sea funcional en una estructura ya de por sí fragmentaria, la puesta deja entrever un mecanismo que brinda unidad al conjunto, sin que todas las escenas lo logren de manera efectiva. A partir del tratamiento escénico de un contenido parateatral, se diseña su representación simbólica; de tal manera que, aunque ese indicio sea reconocible, el mensaje social se potencia por medio de recursos plenamente artísticos: intertextualidad, danza, coreografía, juego de luces (tanto las dirigidas desde cabina como las portátiles), monólogos, testimonios biográficos y secuencias en donde el trazo y la interpretación protagonizan el éxodo masivo en la unidad de cada cuerpo actoral. Telón de Arena da vida a historias particulares, a travesías interrumpidas, a casos concretos de quienes ordenan con cuidado y esmero la vida entera en los lindes de una mochila.

Tras el ataque terrorista perpetrado en agosto de 2019 en Cielo Vista Mall, en El Paso, en respuesta a la "invasión hispana de Texas" (según palabras del tirador), en el que 22 personas -entre ellas siete mexicanos - murieron, la presión de activistas consiguió que el evento Abrazos no Muros se festejara de nuevo. El pasado 26 de octubre, habitantes y familias fronterizas, separados por procesos jurídicos de índole migratorio, volvieron a practicar un simple gesto de afecto durante tres minutos (ya no cinco). La 
ceremonia de abrazos, mismo acto con el que cierra la obra de Perla de la Rosa cuando los actores bajan a interactuar con el público, fue custodiada por varios efectivos, con armas largas, no solo de la Border Patrol, sino también de sus pares, la Guarda Civil, ubicados a la otra orilla (de cualquier ideología próxima a los derechos humanos).

\section{TEATRO BÁRBARO: DEL SÓTANO HASTA MERO ARRIBA}

Conocimos a Teatro Bárbaro en la función inaugural de la MET 26: San Sipriano redentor y los lágrima team, de Raúl Valles, dirigida por Luis Bizarro (Luis Jair Castillo). La puesta en escena cautivó al público juarense. No entendemos por qué la compañía, fundada en 2009 en Chihuahua capital, no ganó ese año. La historia de toda agrupación artística independiente es sinuosa; no obstante, la estrecha amistad entre sus miembros, el compromiso con su arte, la coherencia entre la verdad puesta en las tablas y la ficción vivida a diario (o viceversa), así como el profesionalismo con que despliegan su teatro han allanado el camino para que los Bárbaros se expresen con un lenguaje poético que distingue su quehacer. En cada una de las casi 20 producciones, indagan sobre los elementos y emociones que estrujan, los cuerpos que mueven las conciencias y que incitan a la reflexión para deshabituar y contravenir a la violencia, tan normalizada en nuestro norte.

El periodista Fernando Jordán, en su Crónica de un país bárbaro (1955), delineó las cualidades épicas del ser norteño acordes a las dilatadas extensiones que recorre. El clima, aseguraba, "imprime al hombre septentrional un sello: el de su fuerza; y una característica igualmente precisa: su voluntad. Son exigencias de la tierra y el medio" (1978: 10). Durante la llamada guerra contra el narco, la inseguridad se avecindó en la ciudad de Chihuahua. En medio de ese clímax violento, que parece resurgir de manera intermitente, un puñado de teatreros decidieron hacer cuartel. Su primer foro, un espacio de 6 por 4 metros, ubicado en la populosa avenida 20 de Noviembre, era pequeño pero suficiente para un momento en el que los habitantes no salían a la calle. La zona 
urbana era peligrosa; bares, cantinas y centros nocturnos aledaños sufrieron atentados por negarse a la extorsión o a distribuir droga. ¡Bárbaros aquellos que ensayaban por las noches hasta las primeras horas de la madrugada! Inspirados en la crónica de Jordán, el grupo hizo suyo el vocablo, "sinónimo de un supremo e invencible anhelo por la libertad” (1978: 21).

La compañía se ha mudado en un par de ocasiones. En el Encuentro de Creadores — celebrado en la capital, previo a la MET 27-, Bizarro ofreció un emotivo tour por las distintas sedes. Su segunda locación, en el céntrico callejón de la Séptima, hoy llamado Víctor Hugo Rascón Banda por iniciativa de los Bárbaros ante Cabildo, fue rehabilitada como la "Sala Subterráneo", un "espacio grotescamente hermoso", como lo presume el líder de la compañía. Esa catacumba, a una calle del Palacio de Gobierno, fue el lugar ideal para correr riesgos en cuanto a propuestas escénicas y generar un público asiduo al teatro.

El Foro Cultural Independiente Teatro Bárbaro, en la calle Doblado del primer cuadro de la ciudad, es su domicilio actual en el polígono conformado por el Congreso del Estado, la Catedral y la Presidencia Municipal. Un inmueble amplio —con varias secciones y pisos, un pasillo museográfico y un sinfín de posibilidades creativas en un escenario al que hay que bajar por unas cuantas escalinatas - arropa al elenco estable y a los grupos invitados que nutren la cartelera a lo largo del año. La década invertida al teatro les ha redituado experiencia, proyección internacional y apoyos para la creación, como el programa México en Escena, del que son beneficiarios desde 2014. El amor que profesan hacia las tablas se evidencia no solo en sus procesos colectivos de producción e investigación en donde todos suman, sino en la calidez y responsabilidad con la que reciben a todos aquellos para quienes se brindan. Sin duda, estos Bárbaros tienen a bien el resguardo, a cabalidad, del teatro en el norte; más ahora que, jpor fin!, han sido acreedores al máximo reconocimiento en la MET 28. Pasemos, pues, al análisis del par de obras que montaron en el teatro principal de Delicias. 
La mancuerna entre la dramaturgia del teórico y profesor de teatro de la UACH, Raúl Valles (primer lugar en Dramaturgia del Confinamiento, del Centro Cultural Helénico) y la dirección de Luis Bizarro ya había probado fortuna en el Estado. Su nueva producción, Derivas, explora la "evolución que se produce en una determinada dirección, especialmente si esta se considera negativa". Esta definición de diccionario, atendida como una luz ante la sobreexposición de estímulos, nos permite trazar una línea de comprensión a través de fragmentos y cuadros de un acontecimiento a priori desarticulado, un montaje que cuestiona el uso de la razón cronológica, pone al límite el ejercicio de expectación y recupera distintas tradiciones dramáticas, desde Un hogar sólido de Elena Garro hasta los ensayos de Alberto Villarreal. Derivas cuestiona un camino infértil, un trayecto nocivo. ¿Qué discursos validan y sustentan la violencia de género?

El dispositivo escénico sobrepasa la mirada. Un extenso corredor se encuentra cercado por la pared de fondo del inmueble y por una butaquería repleta, importada desde el foro de Teatro Bárbaro en la capital del Estado, montada en el escenario principal del edificio (y reutilizada por La Bodega). A los costados vemos la tramoya, los entresijos de la maquinaria. En medio, a lo largo del rectángulo a manera de caja negra, seis presencias absortas, de pie y observando fijamente al auditorio, aguardan a que la experiencia dé inicio, lo cual sucede cuando un sillón azul convoca, de forma centrípeta, la atención, tensión y movimiento.

Un grito sordo se agolpa en la garganta, alarido cubierto por indiferencia. Fuego, aire incendiario. Lenguaje no referencial. Tristeza infantil. Interlocución rota, quebradiza. Golpeteo de la máquina sobre expedientes irresolutos. Diálogos cíclicos que fatigan su significado. Ladridos. 1990. Estática sobre ruido blanco. Caen las bragas de una niña al saltar la cuerda. "¿Han visto a mis hijas?" Fuerza que distiende miembros y sacude espíritus. "Lo que se dice la muerte no lo puede ocultar". Tambos humeantes. Sonrisas descompuestas en pos de empatía. Gente atrapada en sus escombros. Pies desencajados que irrumpen y vapulean el habla. El intento inservible por recordar. Acciones inhumanas ante un 
fenómeno que nos rompe y abrasa: la desaparición forzada. Sobre esta temática, las cinco actrices —Rosa Peña, Yaundé Santana, Fátima Íseck, Jéssica Verdugo, Valeria Ivonne- y el único actor, Héctor "Magnum" García, atacan con suma neutralidad, cuidado y ritmo solemne un texto compuesto por frases, insinuaciones y escasas secuencias espaciotemporales.

La escena que más nos impactó concentra elementos capitales de cuerpos narrados por la violencia: el azar y la plegaria. Una mujer relata la vejación constante en sus relaciones de pareja. Dios en el ropero atestigua golpes e insultos con parsimonia. Ella se hace de valor para dejar a su esposo e iniciar de nuevo, pero nos confiesa que "me echó en una bolsa hecha pedacitos". Entonces, la deidad se materializa en una caricatura omnipotente, postrando a sus fieles y aceptando rogativas. El bienaventurado juego colectivo comienza; a la entrada al teatro se repartieron tarjetas con seis incisos para responder tres preguntas: 1. Dios, ¿qué has estado haciendo los últimos cinco mil años en los que nos has dejado tan solos? Una actriz escribe la respuesta en la pared de fondo. 2. ¿Por qué no intervienes y detienes los asesinatos que se cometen contra inocentes? “-Sus respuestas, por favor”. 3. ¿Por qué desaparecen las mujeres en México? “-E. No desaparecen, las desaparecen”. Confiamos que esta respuesta no varíe de función en función ante el aspecto más devastador que se puede ejercer sobre nuestro cuerpo. La indeterminación e incertidumbre al volvernos incógnita nos resta humanidad, nos vuelve cosa, sombras discontinuas a lo largo de lo que alguna vez se llamó biografía.

El trabajo de dirección para todo aquel que se enfrente a la dramaturgia de Raúl Valles debe sopesar la sintaxis de la palabra con el diseño de la partitura escénica, lo escrito en papel con el traslado al órgano palpitante. La ecuación parece ser fructífera para Teatro Bárbaro. No obstante, nos parece que la entrega del mensaje primordial se obscurece entre tanto artificio. De ahí que la ceremonia de cierre, si bien esperanzadora, catártica y emotiva, resulte tan convencional ("que la paz esté contigo"), e incluso vaya en contra de la propuesta experimental a lo largo del espectáculo. Si el entrenamiento de esgrima, por poner solo un ejemplo, dispara 
interpretaciones, el abrazo se significa a sí mismo y no permite oposición. No se nos acuse de indolentes. Como padre y madre, si el gis hubiera llegado a nuestras manos, hubiéramos plasmado en el mural colectivo el terror que nos da que nuestros hijos sientan miedo... que nunca sean solo carne.

El segundo día de la MET, también en Delicias, presenciamos la obra acreedora al máximo galardón: Arrullos para Benjamín, dirigida por Rogelio Quintana, actor deliciense, cofundador de Teatro Bárbaro. Ciertas situaciones, a partir de la pérdida, parecen imposibles de nombrar, aún más de esclarecer para aquellos que apenas comienzan su vida. ¿Cómo explicarle a una niña la ausencia de su padre, cuando no hay razones convincentes? Esta pieza, escrita por Hasam Díaz en 2013 y publicada dos años después en los Cuadernos de Dramaturgia para Joven Público de Paso de Gato, explora una alternativa: la fantasía.

La ambientación lumínica que deambula entre la penumbra y breves destellos potencia un caudal de historias: desde las imaginadas por dos pequeños, paliativos ante el abandono y la tristeza materna, hasta las remembranzas de un adulto (en tiempo futuro) sobre su hermanita. La puesta arranca con Hugo adulto (Armando Seáñez) envuelto en murmullos de la naturaleza y manipulando una mariposa de metal, símbolo de su antigua familia: "Son las que hacen volar los sueños. Él quería que los sueños de mamá volaran muy alto. Pero a veces las mariposas pueden desaparecer" (Díaz: 16). Luego, una cálida luz enmarca el sueño de la tierna Benjamín (Natalia Corral). Si tomamos en cuenta al público infanto-juvenil, el hecho de que la protagonista porte un nombre varonil, con acepción femenina, destantea a quienes dudan de las identidades e ignoran derechos de autor. ${ }^{23}$ La confusión no es menor, ya que se insinúa que el papá abandona el lecho a razón del nacimiento de Benjamín, a quien Hugo recrimina: "No lo puedes conocer porque tú hiciste que se fuera” (Díaz: 32). ¿El padre deseaba otro varón, y por eso ella adoptó un nombre masculino?

23 "Benjamín, na. Por alusión a Benjamín, hijo último y predilecto de Jacob. 1. Masculino y femenino. Hijo menor de una familia” DRAE. 
Hugo mayor y Hugo niño (Jorge Herrera) arrullan el alma de su hermana, a pesar de los reveses; también él nos relata los juegos, cuentos e ilusiones infantiles, escaparates de esperanza, regalos para los cumpleaños. Frente al miedo que deviene del silencio (ausencia paterna, afonía materna), el espectáculo rompe con lo inaudible y dota de confort al sonido de la lluvia, a las polkas y su coreografía, a la canción Colores y, sobre todo, a la cadencia de la voz, aliento y sostén de ambos protagonistas.

Las acciones se desencadenan a partir de las memorias de Hugo adulto, las cuales cargan de emoción a objetos que, desde la primera escena, representan la doble pérdida del personaje en tiempos dispares: la mariposa y la baraja lo ayudan a mantener el recuerdo de su padre; la muñeca de trapo y una resortera, el de su familia entera. Hugo niño ocultaba su sentir en gritos, insultos y sobreprotección hacia su hermana; el mayor, por su carácter de narrador, reconoce necesario nombrar aquellas cosas que resquebrajan el espíritu, pero que guardan cierta luz, aunque sea onírica: "Llego. A esa hora cuando la noche es muy oscura, pero veo el cielo. Lo contemplo y hay dos lunas, dos lunas brillantes. Entonces ahora todo es más claro. Todo brilla" (Díaz: 3).

El deambular entre la fantasía y la realidad también se cimienta con el dispositivo escénico; el cúmulo de sentimientos, ensoñaciones y recuerdos recorre los espacios diseñados por Héctor "Magnum" García: hojas secas alrededor de un par de tambos, una carretilla y un mostrenco multifuncional al centro. La estética sombría, de estío, remite a un ambiente serrano, norteño, en donde los problemas de seguridad han quebrantado cientos de familias. La mariposa de metal, una vieja baraja y los constantes arrullos concitan el simbolismo idóneo para poner en escena ciertos cataclismos. Retomar estas problemáticas desde la visión pueril resulta imprescindible, ya que desdeñar su forma para sobrellevar la ausencia cancela también su resiliencia. En Arrullos para Benjamín, el amor entre hermanos, envuelto en un velo de fantasía, se convierte en columna para soportar los sinsabores familiares.

Amén de la dramaturgia de Díaz y la dirección de Quintana, sobresale la actuación y trabajo corporal de Natalia y Jorge, quie- 
nes encarnan, con naturalidad expresiva y juguetona, los binomios que los erigen: tristeza/alegría, desesperación/ilusión, soledad/hermandad e inocencia/toma de conciencia hacia la adultez. La convergencia entre la fuerza del texto, la estética de la producción, la dirección escénica y la intensidad histriónica de nuevos talentos fue la responsable de que Arrullos para Benjamín se posicionara como la obra representante de Chihuahua en la MET 28. Ya en 2018, Teatro Bárbaro había sido descalificado por la participación de una menor de edad en La luz de las ausencias, montaje que pudo haber competido por reconocimientos. Esta vez, la gestión y la norma -el trabajo de escritorio- no han impedido el justo galardón para los Bárbaros.

\section{CONCLUSIONES: SE ABRE EL TELÓN}

El vistazo sobre las trayectorias de las compañías, tanto las más jóvenes como las ya consolidadas, nos lleva a reconocer un contexto competitivo en el que los múltiples recursos (becas, premios, fideicomisos) otorgados por instituciones federales o estatales, sobre todo en una época en la que los recortes presupuestales a la cultura no cesan, significan la posibilidad de desarrollo y profesionalización para la actividad dramática. Nos parece que la MET 28 mostró un alto nivel de profesionalidad en cuanto a propuestas, estéticas y resoluciones en el escenario.

A pesar de ello, Chihuahua no tuvo representación en la 40 Muestra Nacional de Teatro, celebrada en noviembre de 2019 en Colima. La Dirección Artística del evento no vio en las carpetas de Telón de Arena (King Tiger, A la orilla del río, Los de afuera y Los muertos), de 1939 Teatro Norte (Millenials y El caimán y los sapos), ni de Teatro Bárbaro (Derivas y La luz de las ausencias) las cualidades suficientes para salir del norte. En cambio, la 40 MNT optó por un centralismo desmesurado (11 puestas de 34 procedían de la capital y su zona conurbada) y por temas redundantes, coincidentes con los programas asistencialistas de la Cuarta Transformación. 
Celebramos el esfuerzo por descentralizar la MET en un Estado que -contra toda razón matemática - tiene dos núcleos; no obstante, los teatristas deben presentar su trabajo en igualdad de condiciones, en edificios equipados para montar espectáculos profesionales. ${ }^{24}$ Nos dio gusto compartir butacas con un auditorio no asiduo al teatro, como en Saucillo, pero esos espectadores más que una producción traída de la capital, necesitan estímulos y programas artísticos para ocupar su inmueble no solo como público sino con la generación de actividades escénicas; en este contexto, el sistema de refrigeración sería un requisito más en un municipio con las condiciones para recibir compañías y exhibir su teatro.

Apoyamos el espíritu de inclusión al programar espectáculos amateurs; sin embargo, la competición con compañías profesionales los deja en clara desventaja. El dictamen del jurado respalda tal afirmación. ${ }^{25}$ Reiteramos que el formato de premiación también debe ser rediseñado a favor del diálogo y la anuencia colectiva. "Los propios creadores, auxiliados por observadores externos - ya no como jurado [sino como asesores]-, pueden llegar a un consenso para designar la propuesta representativa” (Montiel, 2019: 192). Sin duda, los pequeños grupos que escriben, dirigen e incluso protagonizan sus obras deben seguir asistiendo a la MET para vincularse con sus pares, presenciar todos los montajes, asistir a los talleres con los especialistas y mostrar su trabajo en una ca-

24 Durante la función de clausura, a cargo de Telón de Arena la noche del 22 de agosto de 2019, la tormenta del exterior irrumpió en el escenario. El chorro de agua era sonoro. En la ceremonia de premiación, las autoridades se comprometieron a remodelar y reequipar el Teatro de la Ciudad Manuel Talavera, en Delicias, así como otros inmuebles del Estado. La directora Perla de la Rosa, más preocupada por la promesa que por el aplauso, comprometió a Raúl Manríquez Moreno, director de Capital Cultural, y al diputado Jesús Alberto Valenciano García, quienes reiteraron la inversión, mencionando incluso montos y plazos.

25 Los resultados fueron los siguientes. Obra representante, Mejor actor y Mejor escenografía: Arrullos para Benjamín (Teatro Bárbaro, Armando Seañez, Héctor "Magnum" García); Obra Suplente y Mejor Dirección: A la orilla del río (Telón de Arena, Perla de la Rosa); Mejor Dramaturgia Original y Mejor Actriz: Millenials (1939 Teatro Norte, Estefanía Estrada); Mejor Iluminación: Soy Bernarda Alba (La Bodega); y Mejor Vestuario: King Tiger (Telón de Arena). 
tegoría especial para recibir retroalimentación de cara al largo y consistente camino hacia la profesionalización.

Escribimos estas líneas en medio de una contingencia sanitaria que ha trastocado ritmos y rutinas (como los de la investigación documental). Los teatros en todo México han cerrado desde hace semanas, interrumpiendo temporadas y alterando tiempos de producción. Cuando el cuerpo del otro representa un riesgo de contagio, ¿qué lugar ocupa el convivio teatral? ¿Se puede hacer teatro durante la pandemia? En este clima de incertidumbre, en el que parece inminente la cancelación de las muestras estatales y la nacional, el teatro mexicano -y dentro de él el chihuahuenseexplora las posibilidades de poner su arte a través de las pantallas de nuestros dispositivos. Ya sea con reestrenos o con producciones inéditas, el arte dramático se adapta a la interlocución urgente entre nuestro contexto y las formas de representarnos. Esperamos con ansias la edición número 29 de la MET Chihuahua, ya sea que se aplace en este mismo 2020 o se posponga para el siguiente año, pero que nunca -ni siquiera vacilando- se detenga.

\section{BIBLIOGRAFÍA}

Puestas en escena y textos dramáticos

A la orilla del río, de P. de la Rosa. Dir. P. de la Rosa, Telón de Arena, 21 de agosto 2019, MET Chihuahua, Teatro de la Ciudad Manuel Talavera, Delicias.

Arrullos para Benjamín, de H. Díaz. Dir. R. Quintana, Teatro Bárbaro, 19 de agosto 2019, MET Chihuahua, Teatro de la Ciudad Manuel Talavera, Delicias.

Auroras boreales o nos vemos en Alaska, de V. Loera. Dir. V. Loera y D. López, Los Habitantes Inútiles, 19 de agosto 2019, MET Chihuahua, Teatro Auditorio Presidentes, Saucillo.

Derivas, de R. Valles. Dir. L. Bizarro, Teatro Bárbaro, 18 de agosto 2019, MET Chihuahua, Teatro de la Ciudad Manuel Talavera, Delicias. 
Díaz, H. (2015). Arrullos para Benjamín. Paso de Gato.

Filos, de E. Galindo. Dir. colectiva, Movimiento OT Teatro, 21 de agosto 2019, MET Chihuahua, Teatro de la Ciudad Manuel Talavera, Delicias.

Galindo, E. (2016). Filos. En Antología teatral I (pp. 172-207). UACJ. García Lorca, F. (2008). La casa de Bernarda Alba. Drama de mujeres en los pueblos de España. Ed. B. Rodríguez Gutiérrez. Stockcero.

King Tiger, de P. de la Rosa. Dir. P. de la Rosa, Telón de Arena, 21 de agosto 2019, MET Chihuahua, Teatro de la Ciudad, Camargo.

Loera, Valeria. (2018). Elefante. En V. Bujeiro (ed.), Teatro de la Gruta XVIII (pp. 185-258). Secretaría de Cultura; Fondo Editorial Tierra Adentro.

------. (2019). Planeta Kepler o los datos inútiles; Auroras boreales o nos vemos en Alaska. Instituto de Cultura del Municipio.

Millenials, de E. Galindo. Dir. E. Galindo, 1939 Teatro Norte, 18 de agosto 2019, MET Chihuahua, Teatro de la Ciudad, Camargo.

Soy Bernarda Alba, de F. G. Lorca (adaptación). Dir. Rubén Jordán, La Bodega, 20 de agosto 2019, MET Chihuahua, Teatro de la Ciudad Manuel Talavera, Delicias.

Secundaria

Chávez Marín, J. (2014). Aventuras de coctel. Ichicult.

De la Rosa, P. (2016). Justicia negada. El teatro como acción solidaria. Conjunto, 178, 12-17.

Gobierno del Estado de Chihuahua (2019). Convocatoria Muestra Estatal de Teatro 2019.

------. (2017a). Plan estatal de desarrollo 2017-2021. http://www. chihuahua.gob.mx/contenidos/plan-estatal-de-desarrollo-2017-2021-0.

------. (2017b). Programa sectorial de cultura como derecho humano, Chihuahua 2017-2021 (No. 65). http://ihacienda.chihuahua. gob.mx/tfiscal/indtfisc/progsec17/anexo065-2017cultura.pdf 
Jordán, F. (1978). Crónica de un país bárbaro. Centro Librero La Prensa.

Lara, I. (2019). "El territorio de la soledad". En V. Loera, Planeta Kepler o los datos inútiles; Auroras boreales o nos vemos en Alaska (pp. 13-14). Instituto de Cultura del Municipio.

López Tijerina, R. (1978). Mi lucha por la tierra. FCE.

Márquez, G. (4 de agosto, 2019). Danza aérea y risa para los niños [Reseña de De niños, cacas y criaturas extrañas, de M. Vera y R. Ríos]. Norteatro. http://norteatro.com/wp/1860-2/.

-. (14 de abril, 2020). A ocho meses de la MET 28 en Chihuahua. Norteatro. http://norteatro.com/wp/a-ocho-meses-dela-met-28-en-chihuahua/.

Montiel Contreras, C. U. (2019). La Muestra Estatal de Teatro de Chihuahua 2018: desmontajes y reseñas. Investigación Teatral, 15 (10), 178-193.

Padilla Delgado, H. y G. de la Mora. (2011). “La reconstrucción del tejido social desde la cultura. El caso de Telón de Arena en Ciudad Juárez". Chihuahua Hoy, 9, 217-251.

Padilla Delgado, H. (2005). Telón de voces: el teatro en Ciudad Juárez 1980-2002. Gobierno Municipal de Ciudad Juárez.

Partida Tayzan, A. (2008). "Chihuahuenses en la Muestra Nacional de Teatro". Solar, 62, 41-49.

Salazar Mendoza, M. (2010). "Detonantes para la escritura en Ciudad Juárez hoy". Chihuahua Hoy, 8, 139-165.

Sierra, L. (2016). A telón abierto: 25 años de la MET [documental]. Secretaría de Cultura de Chihuahua y Sierra Media Labs.

Velo, V. (2015). La narraturgia: teatro narrativo y su lugar en la representación. Ichicult. 